\title{
Capsule Commentary on Prouty et al. Providers' Perceptions of Communication Breakdowns in Cancer Care
}

\author{
Janice B. Foust, PhD, RN \\ Department of Nursing, College of Nursing and Health Science, University of Massachusetts Boston, Boston, MA, USA.
}

J Gen Intern Med 29(8):1163

DOI: $10.1007 / \mathrm{s} 11606-014-2797-\mathrm{x}$

(c) Society of General Internal Medicine 2014

$\mathrm{P}$ routy and colleagues ${ }^{1}$ aptly describe the complexities faced by healthcare professionals when communicating with patients and colleagues about cancer care. The providers identified communication barriers at three levels: patient, provider and healthcare system. They recommended specific strategies to individualize and facilitate teamfocused communication within healthcare systems. Healthcare professionals ideally pace the delivery of information so patients can absorb information and ask questions that are relevant to them. Patients and families value timely information that is clear, accurate and sufficiently detailed ${ }^{2}$. A recent Institute of Medicine (IOM) report ${ }^{3}$ presented an adapted cancer care continuum that could be useful to frame communication germane to the patient's immediate clinical situation. Information and its delivery should be tailored to the clinical context of a patient's cancer experience along the continuum of receiving a new diagnosis, news of a recurrence, managing symptoms, being a survivor or facing issues of end-of-life care. Providers' identified challenges of balancing hope and reality ${ }^{1}$ without referring to the effect clinical context has on such communication. Additional research would help depict both common and changing informational needs of patients as they progress along the cancer care continuum. Such knowledge would facilitate professionals taking a proactive approach by engaging patients in open conversations to screen for typical phase-specific concerns and then tailor information to meet the patient's specific needs and clinical situation.

The IOM report ${ }^{3}$ described an aging population and its effect on future cancer care. This trend means older patients are likely to experience cancer as one of multiple diagnoses requiring greater coordination of care ${ }^{4}$. One study reported cancer survivors being followed by primary care physicians were more likely to have multiple comorbidities than those followed by subspecialists ${ }^{5}$. Interestingly, providers in this study did not identify the patient's age or comorbidities per se as factors affecting cancer communication ${ }^{1}$. And yet, their examples of information gaps between primary care physicians and oncologists highlight problems in coordinating care for this population. In summary, ideal and effective cancer care communication capitalizes on healthcare providers' expertise and interpersonal skills to tailor proactive, compassionate conversations with patients within the context of a cancer care continuum.

Conflict of Interest: The author declares that she does not have a conflict of interest.

Corresponding Author: Janice B. Foust, PhD, RN; Department of Nursing, College of Nursing and Health Science, University of Massachusetts Boston, Boston, MA 02125, USA (e-mail: Janice.foust@umb.edu).

\section{REFERENCES}

1. Prouty CD, Mazor KM, Greene SM, Roblin DW, Firneno CL, Lemay CA, Robinson BE, Gallagher TH. Providers' perceptions of communication breakdowns in cancer care. J Gen Intern Med. 2014. doi:10.1007/s11606014-2769-1.

2. Mazor KM, Beard RL, Alexander GL, Arora NK, Firneno C, Gaglio B, Greene SM, Lemay CA, Robinson BE, Roblin DW, Walsh K, Street RL Jr, Gallagher TH. Patients' and family members' views on patientcentered communication during cancer care. Pyscho-Oncology. 2013;22:2487-95. [Published online June 2013 in Wiley Online Library] doi: $10.1002 /$ pon. 3317 .

3. Institute of Medicine (IOM). Delivering high-quality cancer care: Charting a new course for a system in crisis. Washington, DC: The National Academies Press; 2013.

4. Hurria A, Naylor M, Cohen HJ. Viewpoint: Improving the quality of cancer care in an aging population: Recommendations from an IOM Report. JAMA. 2013;310(17):1795-6.

5. Haggstrom DA, Arora NK, Helft P, Clayman ML, Oakley-Girvan I. Follow-up care delivery among colorectal cancer survivors most often seen by primary and subspecialty care physicians. J Gen Intern Med. 2009;24(Suppl 2):472-9. 